\title{
Effect of the Addition of Soy Protein (Glycine Max Merryl) on the Composition of Cooked Ham
}

\section{Efecto de la Adición de Proteína de Soya (Glycine Max Merryl) en la Composición de Jamón Cocido}

I International Seminar of Livestock and Agroindustrial Production ESPOCH 2020

Corresponding Author:

E. Romero Machado

eromero@espoch.edu.ec

Published: 2 September 2021

Production and Hosting by

Knowledge E

(c) E. Romero Machado et al. This article is distributed under the terms of the Creative Commons

Attribution License, which permits unrestricted use and redistribution provided that the original author and source are credited.

\section{E. Romero Machado, T. Zambrano Núñez, and P. Pino Falconí}

Escuela de Gastronomía, Facultad Salud Pública, Escuela Superior Politécnica de Chimborazo, Riobamba, Ecuador

\section{Abstract}

The present study aimed to assess the bromatological composition when soy protein was added in the preparation of cooked ham. An experimental approach was used. There were three treatments in which $2.50 \%$ (T1), $5.00 \%$ (T2) and $7.50 \%$ (T3) soy protein was added; these were compared to a control treatment (TO). A randomized design was applied and means were analyzed according to Tukey at 5\%. The following laboratory tests were carried out in the ham finished product: bromatological analysis, microbiological analysis and sensory analysis. The results obtained were as follows: fiber: $2.27 \%$; humidity: $63.53 \%$; fat: $7.47 \%$; protein: $20.23 \%$; ash: $1.83 \%$; and carbohydrates: $4.68 \%$. Significant differences were found between the addition of $7.50 \%$ of soy protein compared to the $0 \%$ control treatment. It can be concluded from the results that the addition of soy protein to ham increases the content of fiber, fat, protein, ash and carbohydrates, and the best treatment without affecting the characteristics of the finished product is the addition of $7.50 \%$ soy protein.

Keywords: meat products, ham, soy protein.

\section{Resumen}

El presente estudio tiene como objetivo adicionar proteína de soya en la elaboración de jamón cocido y valorar la composición bromatológica. El método utilizado en la investigación es experimental manejando tres tratamientos en los cuales se añadió proteína de soya en 2,50 (T1), 5,00 (T2) y 7,50 (T3)\%, que se los comparó a un tratamiento control (TO), se aplicó un diseño completamente al azar y separación de medias según Tukey al 5\%, en el jamón como producto terminado, se realizaron las siguientes pruebas de laboratorio; análisis bromatológico, análisis sensorial. Los resultados obtenidos de fibra (2,27\%), humedad $(63,53 \%)$, grasa $(7,47 \%)$, proteína $(20,23 \%)$, ceniza $(1,83 \%)$ y carbohidratos $(4,68 \%)$, se encontró diferencias significativas entre la adición de 7,50\% de proteína de soya frente al tratamiento control $0 \%$. Con los resultados se puede aludir que las formulaciones de jamón con adición de proteína de soya, aumenta los contenido de fibra, grasa, proteína, ceniza y carbohidratos en relación a un tratamiento control, se puede establecer que el mejor tratamiento es con la adición del 7,50\% de proteína de soya sin que afecte las características del producto terminado.

Palabras Clave: productos cárnicos, jamón, proteína de soya. 


\section{Introducción}

La industria cárnica en la actualidad ocupa el cuarto sector industrial de nuestro país y el primer lugar de toda la industria de alimentos y bebidas [1]. La elaboración de productos cárnicos como es el jamón en nuestro país, es un producto de consumo masivo, está elaborado con carne de: Cerdo, res, pollo, pavo; curado en seco y/o salmuera, condimentado, ahumado o no y cocido [2]. La característica final de los productos puede variar, tanto por la materia prima elegida, y por los diferentes métodos con los que son elaborados [3]. El jamón debe tener textura homogénea y firme, de manera que se pueda rebanar con facilidad, la carne con la que se elabore debe estar en perfecto estado de conservación, descendientes de animales sanos, faenados bajo control sanitario [2]. La cura en salmuera es el método más utilizado para elaborar jamones, es añadir sal, nitrato de sodio o de potasio (o salitre), nitritos y algunas veces azúcar, condimentos, fosfatos y sustancias que aceleran el curado [4]. Este método introduce en la carne fresca una solución de salmuera para curarla antes de la cocción [5].

La soya es una de las principales fuentes de proteínas vegetales que es de gran consumo a nivel mundial [6]. La soya tuvo su origen en el oriente asiático (China) y su domesticación se inició de 17001100 a.C [7]. Después se expandió a otros países de Asia [8]. Con las colecciones de semilla de soya realizadas por botánicos en China y Manchuria, en las últimas décadas del siglo XIX, se distribuyeron semillas a los jardines botánicos y estaciones agrícolas del oeste de Europa y Estados Unidos [9]. La clase botánica encaja al género Glycine, correspondiente al género de las Fabaceae [10].

La soya Glycine max (L.) Merril es una oleaginosa de gran importancia económica en el Ecuador [11], es considerada a nivel mundial como una especie estratégica debido a su composición nutricional, destacándose el alto contenido de proteínas que posee (38 a $42 \%$ ) y el grado de concentración de aceite (18 a $22 \%$ ), por lo que su cultivo es de vital importancia para la industria de aceites vegetales y concentrados para la elaboración de balanceados para alimentación animal [12].

La soya o soja es una semilla que, ha aumentado su popularidad gracias a la tendencia vegana y fitness. Oriunda del Extremo Oriente en lugares como Japón y China, la dieta en estos países se basa en esta oleaginosa [13]. Por valioso valor nutritivo son variados los usos en el consumo humano y animal, tiene un mercado importante en el país, siendo el mayor interesado el sector de la avicultura debido a que representa alrededor del $15 \%$ al $20 \%$ de la composición de los alimentos balanceados [14].

La soya tiene elementos bioactivos que ayudan la salud de las personas, tales como, las isoflavonas que benefician a los síntomas como: Bochorno, fatiga, sudor nocturno, cambios en el estado de ánimo, oscilaciones del humor, sequedad vaginal y dolores de cabeza, auxiliar en prevención y control de la diabetes [15]

La proteína de soja tiene los aminoácidos esenciales precisos para el hombre (los que el cuerpo no puede producir y que, por tanto, se debe consumir a través de la dieta), el contenido en metionina y triptófano es bajo con relación a las proteínas animales, por lo que se integra muy bien con los cereales (que tienen buenas cantidades de esos aminoácidos), logrando así una proteína de cuantiosa calidad [16]. 
El valor nutricional de la harina de soya es: $5,71 \mathrm{~g}$ de grasa total; 49,33 $\mathrm{g}$ de carbohidratos totales; 7,83 $\mathrm{g}$ de fibra dietética; 781,44 $\mathrm{mg}$ de potasio; $231,14 \mathrm{mg}$ de fósforo; 8,13 mg de hierro; 13,81 g de proteína [17].

Diferentes estudios comprobaron que ayuda a reducir el colesterol, disminuye los síntomas de menopausia y la osteoporosis, previene ciertos canceres como el cáncer de mama y endometrio y próstata [18].

Uno de los aspectos que los consumidores de hoy están considerando antes de comprar un producto es el aporte nutricional y los beneficios que este brinde al consumidor, el cuidado de la salud es un aspecto que actualmente está en auge [19].

Por lo expuesto de los productos su gran importancia para los consumidores, se realiza la investigación añadiendo diferentes porcentajes de proteína de soya a un producto cárnico tradicional para mejorar sus características bromatológicas e incentivar la ingesta de diferentes nutrientes alimenticios.

\section{Materiales y Métodos}

La investigación es de tipo experimental se aplicó un diseño completamente al azar, se diseñaron tres tratamientos, $(\mathrm{T} 1=2,5 \%, \mathrm{~T} 2=5 \%, \mathrm{~T} 3=7,5 \%)$ frente a un tratamiento testigo $(\mathrm{TO}=0 \%)$, con tres repeticiones por tratamiento, los tratamientos estuvieron constituidos por los distintos porcentajes de extracto de soya adicionados en la producción del jamón y se ajustaron al siguiente modelo lineal aditivo:

$$
Y i j=\mu+t i+e i j
$$

donde: eee: Valor del parámetro en determinación; e: Efecto de la media por observación; ee: Efecto de los tratamientos; eee: Efecto del error experimental.

\section{Table 1}

Niveles de adición de proteína de soya para la elaboración de jamón cocido.

\begin{tabular}{|l|l|l|l|l|l|l|l|l|}
\hline Ingredientes & $\mathbf{0 , 0} \%$ & $\mathbf{g}$ & $\mathbf{2 , 5} \%$ & $\mathbf{g}$ & $\mathbf{5 , 0} \%$ & $\mathbf{g}$ & $\mathbf{7 , 5} \%$ & $\mathbf{g}$ \\
\hline Carne de cerdo curada & 100 & 1000 & 100 & 1000 & 100 & 1000 & 100 & 1000 \\
\hline Proteína de soya & 0,0 & 0,0 & 2,5 & 25 & 5,0 & 50 & 7,5 & 75
\end{tabular}

La proteína de soya empleada en la producción de jamón se obtuvo siguiendo la metodología de extracción indicada por Toapanta [20], la harina que se emplea en el proceso previamente debe ser desengrasada para luego ser expuesta a un tratamiento con $\mathrm{NaOH} 2 \mathrm{~N}$, posterior agitación, centrifugación y finalmente el tratamiento ácido con $\mathrm{HCl} 2 \mathrm{~N}$. La proteína de soya tuvo una composición de: Humedad 11,6\%, proteína 59\%, fibra $9 \%$, grasa $11 \%$, ceniza $1,9 \%$ y ELN (extracto libre de nitrógeno) $8,5 \%$.

Mediciones experimentales en el jamón como producto terminado, se realizaron las siguientes pruebas de laboratorio. 


\subsection{Análisis proximal}

- Contenido de fibra (\%)

- Contenido de humedad (\%)

- Contenido de proteína (\%)

- Contenido de grasa (\%)

- Contenido de cenizas (\%)

- Contenido de carbohidratos (\%)

\subsection{Análisis sensorial}

- Escala hedónica (7 puntos)

- Prueba de preferencia, 4 opciones

\subsection{Análisis estadísticos y prueba de significación}

Los análisis estadísticos aplicados a las pruebas nutricionales y sensoriales del experimento son las siguientes:

- Análisis de varianza (ANOVA) para las diferencias de medias.

- Separación de medias de acuerdo con la prueba de Tukey al nivel de significancia $P<0,05$.

- Análisis de regresión.

- Estadística descriptiva para la valoración microbiológica.

- Estadística descriptiva para la cuantificación de aminoácidos.

Estadística sensorial cárnicos con proteína de soya.

Se utilizó un análisis de varianza basado en la escala hedónica de 7 puntos, (3, 2, 1, 0 , $-1,-2,-3)$, además de un comparativo de medias de Tukey, de los cuales se presenta un gráfico de barras como referencia.

\subsection{Análisis de bromatológicos de laboratorio}

\subsubsection{Análisis de fibra}

- Cerciorarse que exista un sistema de vacío.

- La muestra para este tipo de análisis debe ser completamente seca.

- La muestra debe ser alrededor de 1 a $2 \mathrm{~g}$.

- Este método mide cantidades variables de celulosa y lignina en la muestra.

- La hemicelulosa, pectinas y los hidrocoloides son solubilizados sin ser detectados por esta razón este método es considerado como descontinuado. 


\subsubsection{Análisis de humedad}

El equipo que nos permitirá realizar este análisis es la estufa, cabe recalcar que debemos eliminar la mayor cantidad de agua del alimento garantizando de esta manera la estabilidad del alimento útil para los siguientes análisis.

La estufa que nos permitirá realizar una humedad inicial es la estufa a $65^{\circ}$, debemos cerciorarnos de que la estufa esté calibrada a esta temperatura.

Una vez que este eliminada la humedad total del alimento sometemos a una segunda humedad garantizando que esté completamente sin humedad, sometiéndole a una porción del alimento a una estufa de $105^{\circ}$ para luego realizar por medio de un cálculo la perdida de humedad total.

\subsubsection{Análisis de proteína}

El proceso de laboratorio para la identificación del contenido de proteínas, se lo realizó en 3 etapas:

- Etapa de digestión

- Etapa de destilación

- Etapa de la titulación

\subsubsection{Análisis de grasa}

- Cerciorarse que exista un sistema de vacío.

- La muestra para este tipo de análisis debe ser completamente seca.

- La muestra debe ser alrededor de 1 a $2 \mathrm{~g}$.

- Para realizar el respectivo pesaje debe someterse a un desecador para que no haya alteración en los datos.

\subsubsection{Análisis de cenizas}

Los alimentos contienen pequeñas cantidades de materiales inorgánicos que varían en composición. Estos se determinan en conjunto como residuo después de calcinar la muestra a $550-600^{\circ} \mathrm{C}$.

\subsubsection{Análisis sensorial}

La evaluación se realizó a partir de las características cualitativas del jamón tales como sabor, color, olor, textura y aceptabilidad. Para esto, el producto se cortó en trozos de $1,5 \mathrm{~cm}$ de largo, identificadas con números aleatorios de tres cifras diferentes para cada uno de los tratamientos. Para la realización de la evaluación sensorial del jamón, se tomó como grupo de estudio a 30 personas (jueces consumidores), sin discriminar edad 
o género. El número mínimo de jueces tipo consumidor para que una prueba sea válida es 30 personas [21]. Se emplearon dos plantillas señoriales: prueba de determinación del grado de satisfacción (escala hedónica de 7 puntos) y prueba de determinación de aceptación general.

\section{Table 2}

Aditivos para la elaboración de jamón - Salmuera.

Aditivos (salmuera)
Agua
GMS
Ajo en polvo carne
Comino en polvo
Pimienta en polvo
Mostaza
Jugo de naranja agria
Vino blanco
Sal fina
Ácido ascórbico
Nitrito
Polifosfato

\begin{tabular}{ll} 
Cantidad \% & g o $\mathbf{~} / \mathbf{k g}$ de carne \\
\hline 83,75 & 800 \\
0,1 & 1 \\
0,3 & 3 \\
0,2 & 2 \\
0,2 & 2 \\
0,02 & 0,2 \\
0,2 & 2 \\
\hline 7,8 & 75 \\
\hline 5,2 & 50 \\
\hline 2 & 20 \\
0,02 & 0,25 \\
0,01 & 0,1 \\
0,2 & 2 \\
\hline
\end{tabular}

Proceso de elaboración

- Recepción de la materia prima y aditivos: Se observó la calidad mediante un análisis organoléptico, se utilizó carne magra de cerdos jóvenes con poco tejido conectivo, las cuales deben estar refrigeradas, las piezas de carne se receptaron a una temperatura máxima de $4^{\circ} \mathrm{C}$.

- Controlar la contaminación microbiana.

- Refrigeración de las piezas.

- Deshuesado y descortezado: Se separó la carne del hueso y luego descortezamos.

- Inyección: Una vez realizada la salmuera se inyectó cada dos centímetros en dirección al hueso.

- Trozado: Se cortó la carne en cubos de $3 \times 3 \mathrm{~cm}$.

- Curado: Se maceró la carne en la tina con salmuera durante 24 hr.

- Masajeado: Se mezcló la carne junto con la proteína de soya durante 2 hr en la mezcladora.

- Prensado: Se colocó la mezcla en los moldes para jamón la mezcla y prensamos.

- Cocción: Se la realizó la cocción durante $12 \mathrm{hr}$ a una temperatura de $75^{\circ} \mathrm{C}$. Debemos tener cuidado con la temperatura no debe pasar los $85^{\circ} \mathrm{C}$ ni bajar de los $70^{\circ} \mathrm{C}$. 
- Enfriamiento: Una vez llena con agua y hielo la tina de enfriamiento se procedió a colocar los moldes.

- Almacenamiento: Sacamos las piezas de jamón de las prensas y se almacenó en refrigeración para evitar la proliferación de microorganismos.

\section{Resultados y Discusión}

\subsection{Fibra (\%)}

Los resultados obtenidos en los diferentes tratamientos de adición de extracto de soya en la elaboración del jamón son 0,00 (T0), 1,23 (T1), 2,07 (T2) y 2,27 (T3), en el estudio estadístico realizado dio como resultado que los tratamientos dos y tres difieren significativamente del tratamiento uno y control.

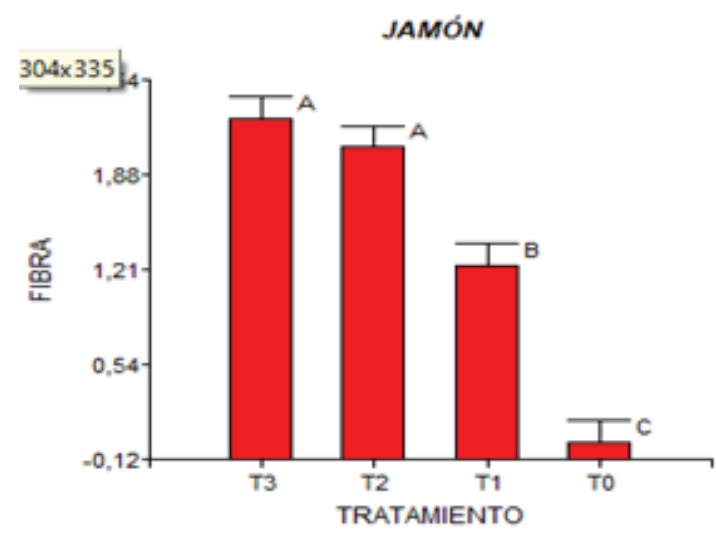

Figure 1

Fibra de jamón con adición de extracto de soya. Medias con una letra común no son significativamente diferente $(p>0,05)$.

El uso de algunas fibras dietéticas en productos cárnicos ha sido investigado a fin de proponerlas como ingrediente en alimentos saludables [22], gracias a su estructura química, las fibras vegetales presentan una serie de ventajas, como una retención de agua y un aumento en la textura de los productos. Hoy están siendo empleadas en productos cárnicos como suplentes de materia grasa, para disminuir el aporte calórico [23], el aporte de fibra en el producto está directamente relacionado al incremento en el porcentaje de extracto de soya.

\subsection{Humedad (\%)}

La humedad del jamón elaborado con los tratamientos T0, T1, T2 y T3 fue de 58,08; 72,$07 ; 69,13 ; 66,73$ y $63,53 \%$, valores difieren significativamente siendo T0 el resultado con mayor valor, de este modo se puede aludir que la adición de proteína de soya en la formulación del jamón influyó en el contenido de agua de este producto cárnico. 


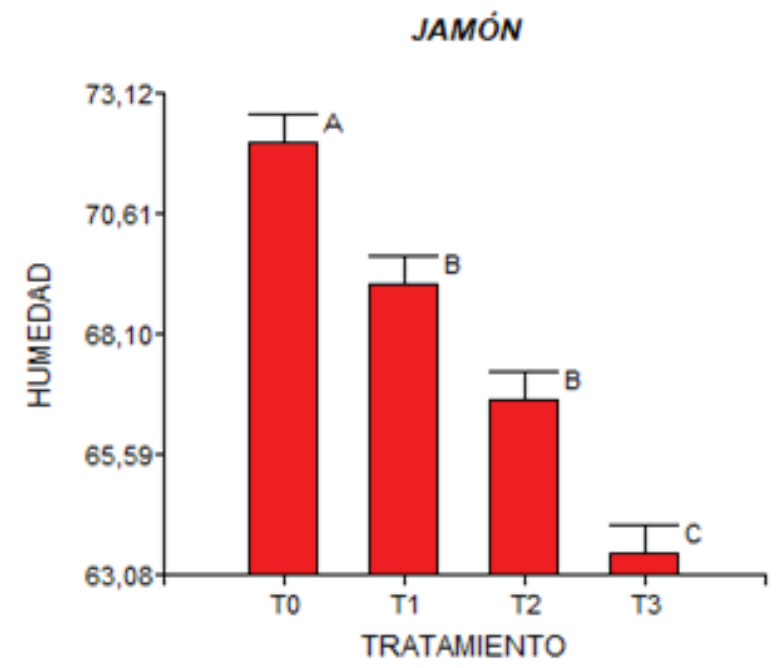

Figure 2

Humedad de jamón con adición de extracto de soya. Medias con una letra común no son significativamente diferente $(p>0,05)$.

El jamón debe registrar un máximo de $72 \%$, de humedad, por lo que cabe señalar que el producto cárnico elaborado se encuentra dentro de lo señalado en la legislación ecuatoriana [24], al utilizar extractos y sustancias de origen vegetal de extracto de soya [25], en diferentes porcentajes reportaron contenidos de humedad de 72,07 y $63,53 \%$, es posible que la adición del extracto de soya vaya disminuyendo la humedad del producto, en comparación con un estudio realizado de jamón cocido utilizando coloraste de tuna el cual contiene $71,86 \%$ de humedad [26], nuestro producto se encontraría en parámetros similares.

\subsection{Grasa (\%)}

La elaboración del jamón con pierna de cerdo en los cuatro tratamientos dio como resultado 6,47 (T0); 6,80 (T1); 7,17 (T2) y 7,47 (T3) siendo en mejor tratamiento en último.

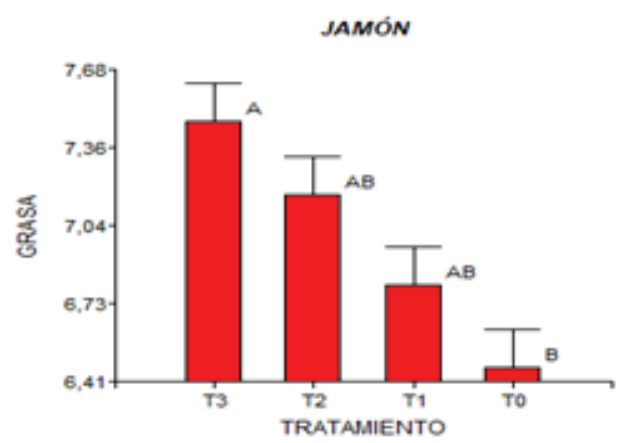

Figure 3

Grasa de jamón con adición de extracto de soya. Medias con una letra común no son significativamente diferente $(p>0,05)$. 
El contenido de grasas y la composición de los ácidos grasos en el jamón [27], contribuye de un modo marcado a la calidad de los productos cárnicos curados [28], en el estudio existen un aumento por cada tratamiento, la carne de cerdo tiene ácidos grasos saturados $3,49 \%$, ácidos grasos monoinsaturados $4,49 \%$ y ácidos grasos poli insaturados 1,65\%, el jamón registra valores entre 6,47 (T0) y 7,47 \% (T3) de grasa [29], se debe a que la proteína de soya añadida posee el $11 \%$ en ácidos grasos poli insaturados de origen vegetal y no contiene colesterol [30].

\subsection{Proteína (\%)}

La adición de proteína de soya en la elaboración del jamón permitió registrar 20,23\% de proteína en el tratamiento 3 , valor que difiere significativamente $(p<0,01)$, del resto de tratamientos, especialmente del control en el cual se estableció 18,30\% de proteína.

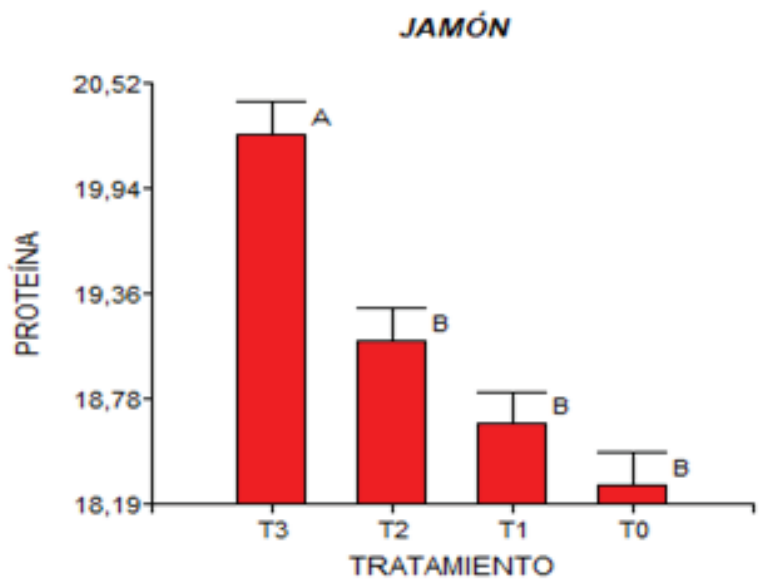

Figure 4

Proteína de jamón con adición de extracto de soya. Medias con una letra común no son significativamente diferente $(p>0,05)$.

En el análisis realizado existe un incremento sustancial de proteína comparando el tratamiento control con el tratamiento de 7,50\% (T3) de adición de proteína de soya, el cual registra el valor máximo de proteína alcanzado con $20,23 \%$, la carne de cerdo tiene el $18,4 \%$ de proteína [29] lo cual se demuestra en el producto terminado con $18,3 \%$ (TO), la proteína de soya que se adicionó en el presente estudio tiene 59\%, al aumentar los porcentajes de proteína de soya [31], este valor va elevando los niveles en proteína vegetal. En estudios realizados los resultados encontrados donde la cantidad de proteína aportada por el extracto de soya en los productos elaborados es alto porcentaje de proteína lo que concuerda con el presente estudio [32].

\subsection{Cenizas (\%)}

El jamón elaborado con la adición de diferentes porcentajes de proteína de soya, registró 1,$03 ; 1,47 ; 1,63$ y $1,83 \%$ de cenizas respectivamente, los valores de los tratamientos 
(T1, T2 y T3) no difieren significativamente, encontrándose mayor contenido de cenizas en el tercer ensayo.

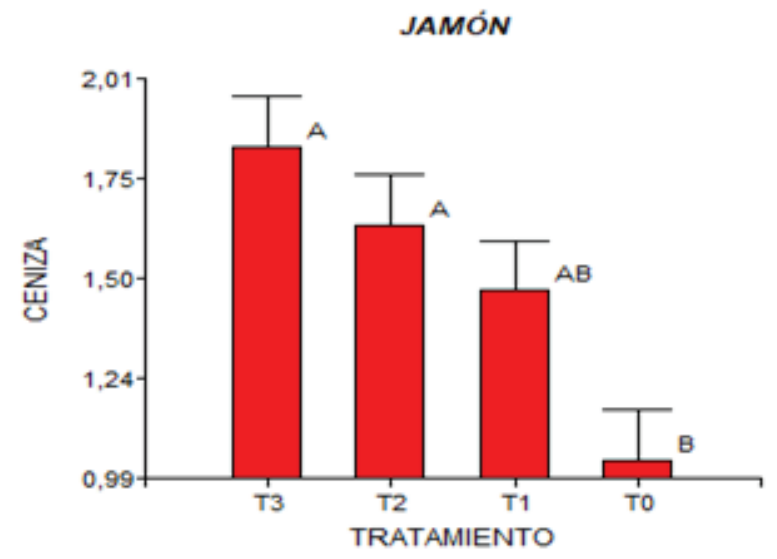

Figure 5

Ceniza de jamón con adición de extracto de soya. Medias con una letra común no son significativamente diferente $(p>0,05)$.

Según la Norma INEN 1339:96, el jamón debe alcanzar un valor máximo de 2\% en ceniza, los análisis de laboratorio dieron como resultado 1,83\% en el último tratamiento de adición de proteína de soya, lo que implica que se encuentra dentro del rango de la Norma Ecuatoriana.

\subsection{Carbohidratos (\%)}

La utilización de extracto de soya en los tratamientos T0, T1, T2 y T3, tuvo los siguientes resultados 2,$12 ; 2,73 ; 3,31$ y $4,68 \%$ de carbohidratos los cuales al realizar el estudio estadístico y de varianza registró diferencias significativas en el tercer tratamiento con respecto a los demás.

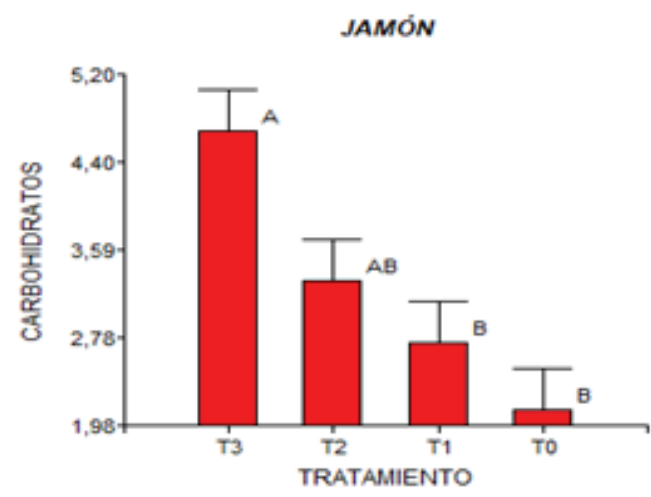

Figure 6

Carbohidratos de jamón con adición de extracto de soya. Medias con una letra común no son significativamente diferente $(p>0,05)$. 
En el presente estudio se encontró contenidos de carbohidratos en el producto final de entre 2,12 y $4,68 \%$, no existe un parámetro establecido en la Norma NTE INEN 1338:2012 de productos cárnicos para poder compararlo, en un estudio realizado de elaboración de jamón cocido a partir de Carne de Paiche Amazónico (arapaima gigas) se obtuvo un total de carbohidratos de 1,36\% [33], en nuestro estudio los porcentajes son superiores inclusive en el tratamiento con menor adición de proteína.

\subsection{Análisis sensorial}

Según el grupo de catadores que determinaron el grado de satisfacción del jamón elaborado con la adición de diferentes porcentajes de extracto de soya, dio como resultado 7 (T0), 7 (T1), 10 (T2) y 6 (T3), valores que al ser sometidos al estudio estadístico y de varianza no proyecta diferencia significativa ( $p$-valor 0,8284$)$, de esta manera se puede mencionar que la adición de proteína de soya en el producto no influyó en la percepción del consumidor sobre del jamón.

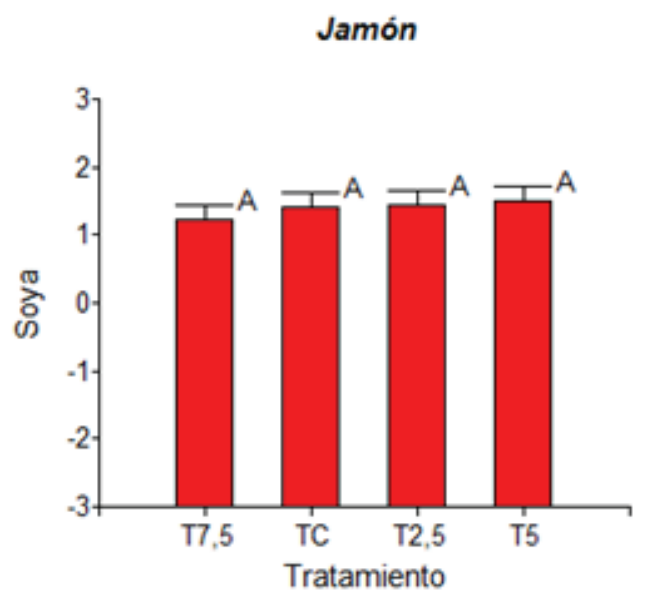

Figure 7

Análisis sensorial de jamón con adición de extracto de soya. Medias con una letra común no son significativamente diferente $(p>0,05)$.

Las propiedades texturales de un alimento son un grupo de características físicas que surgen de la estructura y composición del alimento, Sherman 1970 [4]. El grupo de estudio no estableció una percepción significativa en los tratamientos realizados con la adición de extracto de soya en la elaboración del jamón, pero existe un leve agrado por el tratamiento con $5.00 \%$ de adición de proteína de soya, la aceptabilidad final del producto curado son los relacionados con las características sensoriales valoradas en la caracterización sensorial [34].

\section{Conclusiones}

Las formulaciones de jamón cocido con adición de proteína de soya, aumenta los contenido de fibra, grasa, proteína, ceniza y carbohidratos en relación a un tratamiento 
control, se puede establecer que el mejor tratamiento es con la adición del 7,50\% de proteína de soya sin que afecte las características del producto terminado, en el caso de la humedad este parámetros va disminuyendo en cada adición de proteína sin embargo al llegar al máximo porcentaje no se ve afectado según la Norma Ecuatoriana INEN.

La elaboración del jamón con los diferentes porcentajes de proteína de soya no presenta diferencias para los catadores que degustaron el producto, por lo que se puede decir que la adición de la soya no cambia las características sensoriales del producto final.

\section{Agradecimientos}

A quienes colaboraron abiertamente en la ejecución de este estudio.

\section{Conflicto de Intereses}

Los autores declaran que no tienen conflicto de interés alguno al elaborar el presente artículo.

\section{References}

[1] Bautista M. Influencia del tratamiento térmico moderado. Riunet.upv. 2016. Disponible en: https:// riunet.upv.es/bitstream/handle/10251/69002/BAUTISTA - Influencia del tratamiento térmico moderado utilizando aire caliente en la textura de....pdf?sequence=1\&isAllowed=y

[2] NTE INEN 1 339:96. Carne y productos cárnicos. Jamón. Requisitos. 2006. Disponible en: http://www.dspace.espol.edu.ec/xmlui/bitstream/handle/123456789/10608/inen1339-jamon.pdf? sequence=7\&isAllowed=y

[3] Corona E. Ultrasonidos de señal no destructivos aplicados para la evaluación del porcentaje de grasa fundida en los productos cárnicos curados. Riunet.upv. 2013. Disponible en: https://riunet.upv. es/handle/10251/14063\#.XKOKq7d6BmY.mendeley

[4] Martín A. Evaluación de los cambios texturales provocados por un calentamiento moderado de jamón curado. Impacto de la temperatura y del grado de pastosidad. 2017.

[5] USDA. Jamón y la inocuidad alimentaria. 2012. Disponible en: https://www.fsis.usda.gov/wps/ wcm/connect/Obbf041a-8134-46bd-a97d-c4a630ec167d/Jamon_y_la_Inocuidad_Alimentaria.pdf? MOD=AJPERES\{\%\}OAhttp://www.fsis.usda.gov/wps/portal/informational/en-espanol/hojasinformativas/ preparacion-de-las-carnes/jamon-y-la-inocuidad

[6] Espinoza I. Suplementación de fibra prebiótica en la elaboración de jamón prensado. 2015;4:2.

[7] Roján O, Maqueira L, Torres W. Variabilidad del rendimiento en cultivares de soya (Glycine max L.). Inca. 2019. Disponible en: http://scielo.sld.cu/pdf/ctr/v40n1/1819-4087-ctr-40-01-e08.pdf

[8] Delgado H. Análisis de la combinación de microorganismos bioestimulantes (Micorrizas y Rhizobium) en el cultivo de soya (Glycine max). Universidad Técnica De Babahoyo; 2019.

[9] Valencia R. Soya (glycine Max (I) Merril" Alternativa para los sistemas de producción de la Orinoquia Colombiana. La Libertad: CORPOICA C.I.; 2006.

[10] Enriquez Y. Efecto del extracto hidroalcohólico de la semilla de Glycine max (Soya) sobre la memoria y aprendizaje espacial en rattus rattus var albinus con menopausia inducida. Repositorio.uladech. 2019. Disponible en: http://repositorio.uladech.edu.pe/bitstream/handle/123456789/11406/SEMILLA_ MEMORIA_ENRIQUEZ_FLORES_YASMIN_DIANA.pdf?sequence=1\&isAllowed=y

[11] Peralta M. Producción, comercialización y exportación de soya y sus derivados en el Ecuador 2014 2016. 2019;25.

[12] Instituto Nacional de Investigación Agropecuaria. Soya. Tecnologia.iniap. Disponible en: http:// tecnologia.iniap.gob.ec/index.php/explore-2/molea/rsoya

[13] Ramírez D. Aprende acerca de la Soya - Gastronomia.com Ecuador. 2018. Disponible en: https: //ecuador.gastronomia.com/noticia/8261/aprende-acerca-de-la-soya 
[14] III Censo Nacional Agropecuario. Variedades de soya en el mercado ecuatoriano. Sancamilo. 2001. Disponible en: http://www.sancamilo.com.ec/soya.html

[15] Beneficios de la Soya para la salud. Panificación Latam. 2015. Disponible en: https://www. panificacionlatam.com/index.php/inocuidad/55-salud/3023-beneficios-de-la-soya-para-la-salud.html

[16] Vioque J, Raul Sánchez-Vioque R, Pedroche J, Yust M del M, Millón F. Panificación Latam - Concentrados proteicos de la soja. Panificacionlatam. Disponible en: https://www.panificacionlatam.com/index.php/ sectores/15-cereales/3116-concentrados-proteicos-de-la-soja.html

[17] Sistema Solidario de Comercialización del FEPP. Harinas: Harina de soya; 2019.

[18] Caicedo A, Saltos J. Desarrollo de una bebida tipo café a base de soya. Manabi: Universidad Laica; 2016.

[19] Farias C, Villarruel N, Sánchez A, Lomelí G, Novoa Á, GM. Diseño de un sistema de barreras múltiples para el control del deterioro microbiano de salchicha. 2019.

[20] Toapanta M. Caracterización de aislados proteicos de quinua (Chenopodium quinoa Willd.) y su digestibilidad gástrica y duodenal (in vitro). Universidad Técnica de Ambato; 2016.

[21] ASTM. Pa. ASTM S. Philadelphia; 1968. p. 434

[22] Hidalgo L, García T. Evaluación de las respuestas tecnológicas de un embutido de pollo con adición de fibra. 2017. 23-8.

[23] Freixanet L. Aditivos e ingredientes en la fabricación de productos cárnicos cocidos de músculo entero. Metalquimia. 2016. 27-41.

[24] Vallejo Torres C, Morales Rodriguez W, Soria Velazco R, Espinoza Guerra I, Vera Chang J, Díaz Ocampo R. Suplementación de fibra prebiótica en la elaboración de jamón prensado Prebiotic fiber supplementation in pressed ham production. Rev Amaz Cienc y Tecnol. 2015;4(1):48-65.

[25] Celis A, Mendoza C, Parchón M, Cardona M, Delgado W, Cuca E. Extractos vegetales utilizados como biocontroladores con énfasis en la familia Piperaceae. Agronomía Colombiana. 2008

[26] Almanza M, Ruiz K, Sosa M, Cerón A, Martínez G. Obtención de un jamón cocido de cabra, bajo en nitritos, utilizando un colorante natural de tuna. 2016;1(2):523-8.

[27] Poljanec I, Vidinski P, Novina K, Medić H. El impacto de diferentes genotipos de los cerdos sobre el aroma, el color y la composición de los ácidos grasos del. 2019;12: Disponible en: https://hrcak.srce. hr/index.php?show=clanak\&id_clanak_jezik=334568

[28] López-Bote C, Isabel B, Rey I. Efecto de la nutrición y del manejo sobre la calidad de la grasa en el cerdo. XV Curso Espec FEDNA. 1999;188-93.

[29] Valero T, Del pozo S, Ruiz E, Avila J, Varela G. Guía nutricional de la carne. Fundación española de la nutrición. 2012;16-7.

[30] Morán I, Mejía A, Beltrán F. Industrialización del cultivo de soya. Eumet. 2019.

[31] Albuja L. Elaboración de un embutido escaldado vegetariano a base de chocho (Lupinus mutabilis sweet). 2015;29.

[32] Barco L. Elaboración de bebida fermentada a base del extracto de quinua (Chenopodium quinoa Willd) y soya (Glycine max) con la aplicación de probióticos. Zamorano: Escuela Agrícola Panamericana; 2017.

[33] Castro J, Tisalema J. Elaboración de jamón cocido a partir de carne de paiche amazónico (arapaima gigas). Universidad Técnica de Cotopaxi; 2019.

[34] Solá C. Factores que influyen sobre la aceptabilidad del jamón curado. 2019;58. 